\title{
A Pragmatic-Stylistic Analysis of Fictional Dialogues in Kazuo Ishiguro’s Short Story “Come Rain or Come Shine”
}

\author{
ZHANG Tong-tong \\ Guangdong University of Foreign Studies, Guangzhou, China
}

\begin{abstract}
This study investigates the applicability and effectiveness of pragmatic-stylistic analysis in fictional dialogues. Taking Kazuo Ishiguro’s short story “Come Rain or Come Shine” in Nocturnes: Five Stories of Music and Nightfall as a case study, a detailed analysis of four fictional dialogues in this story has been conducted in the light of the cooperative principle, the im/politeness theory, and the turn-taking theory. The study has shown that pragmatic-stylistics offers a useful analytical tool in guiding readers to stylistically read character speech forms and interpret textual cues in conversation so as to gain a better insight into the characters' traits, their power relationships as well as the acceleration and deceleration in the narrative development.
\end{abstract}

Keywords: pragmatic-stylistic analysis, fictional dialogues, Kazuo Ishiguro, “Come Rain or Come Shine”

\section{Introduction}

In 2017, the Nobel Prize in Literature was awarded to Kazuo Ishiguro, the British novelist and screenwriter, "who, in novels of great emotional force, has uncovered the abyss beneath our illusory sense of connection with the world” (The Official Website of the Nobel Prize, 2017). Born in Nagasaki, Japan in 1954 and immigrating to Britain at the age of five, Ishiguro has come to be recognized as one of the three "Best British immigrant writers". Each of his six novels has earned international fame with a literary prize of some sort. For instance, his very first novel A Pale View of Hills was awarded "Winifred Holtby Prize" by the British Royal Society of Literature; An Artist of the Floating World and The Remains of the Day both won "Booker Prize”. Additionally, his collection of short stories Nocturnes: Five Stories of Music and Nightfall won the Italian "Giuseppe Tomasi di Lampedusa International Literary Prize”.

The present study, by drawing on pragmatic stylistics, conducts a detailed analysis of the fictional dialogues in "Come Rain or Come Shine”, the second short story in Nocturnes. The examination of fictional dialogues is of great significance. First, since nearly all fictions contain large portions of talk between characters, an analysis of how they communicate with each other contributes to the understanding of their relationship. Meanwhile, a character's speech in dialogue can indicate his/her traits through its content and form (Rimmon-Kenan, 2002, p. 63). Therefore, "a stylistic approach to understanding characters should—indeed, must—explore the language that those characters themselves are presented as using” (Bousfield, 2014, p. 118, original italics). As a branch of stylistics, pragmatic stylistics combines the approaches of the two disciplines "to answer questions about how

ZHANG Tong-tong, Ph.D. candidate, Associate Professor, Guangdong University of Foreign Studies, Guangzhou, China. 
(literary) language is used in context and how it contributes to the characterization of the protagonists in a literary piece of art or how power structures are created and so on” (Nørgaard, Busse, \& Montoro, 2010, p. 39).

In this story, Raymond, a middle-aged man, recalls (as the first-person narrator) his experience of staying at his friends Charlie and Emily, the wealthy couple's house in London at their invitation. Among the five short stories in Nocturnes, this one has the largest proportion of dialogues, all meticulously-designed and highly indicative of the three characters' distinctive traits, thus contributing tremendously to the characterization and plot development of the story.

\section{A Pragmatic-Stylistic Analysis of the Fictional Dialogues}

In this part, four extracts of fictional dialogues have been selected for discussion in the light of three theoriesin pragmatics: the cooperative principle, im/politeness theory, and turn-taking theory, guided by two research questions:

(1) In a pragmatic sense, what stylistic devices have been employed in the fictional dialogues?

(2) In what ways do they contribute to the characterization and plot development of the story?

\section{The Cooperative Principle in Fictional Dialogue}

When people converse with each other, they tend to "acknowledge a kind of tacit agreement to operate conversationally towards mutual ends” (Leech \& Short, 2001, p. 295). Grice (1975, p. 57) called it the "Cooperative Principle" and proposed four sets of maxims in conversation to be adhered to:

Quantity:

(1) Make your contribution as informative as is required for the current purpose of exchange;

(2) Do not make your contribution more informative than is required.

Quality:

(1) Do not say what you believe to be false;

(2) Do not say that for which you lack adequate evidence.

Relation: Be relevant.

Manner:

(1) Avoid obscurity of expression;

(2) Avoid ambiguity;

(3) Be brief;

(4) Be orderly.

In reality, however, these maxims are often broken in two ways: violating a maxim and flouting a maxim. In the former situation the speaker may intentionally lie or change the topic but the hearer does not perceive that what is said is breaking the maxim, so s/he may be misled; in the latter circumstance, the hearer is aware that the maxim is being broken and s/he has to deduce the additional meaning underlying what is being said, which constitutes the "conversational implicature" (Grice, 1975, p. 51). Such implicature is often found in the "unexpected reply in an adjacency pair” (Lambrou, 2014, p. 143), as in the following example:

Example (1)

"Look, Charlie, why do I need blinds?” I’d asked that time. "I just want to see out when I wake up. Just the curtains will do fine." 
“These blinds are Swiss,” he said, as though this were explanation enough. (Ishiguro, 2009, p. 41)

After Raymond arriving at the couple's house in London and entering the guest room, Charlie begins to demonstrate his household equipment: the lights, the switches, and the blinds. When Raymond asks such a question, Charlie replies in a rather "irrelevant" way, as he fails to give an explicit answer regarding the purpose of the blinds. In fact, his reply flouts the maxim of relation and constitutes conversational implicature. To successfully work out such conversational implicature, readers should activate their schemata of the real world experience that "Swiss-made" products are associated with high quality, exquisite design, and hence sophisticated lifestyle. Therefore, Charlie's reply is actually intended for showing off his wealth and luxurious lifestyle. These textual cues play a crucial role in characterizing Charlie as a so-called "successful” middle-class man, creating interesting stylistic effects as well as foreshadowing events to come as the story unfolds.

In most cases though, fictional dialogues are a lot more complicated than the above example. It is not uncommon for a conversation to break more than one maxim at a time. For instance, when dining at an Italian restaurant, Charlie initiates the conversation with Raymond.

Example (2)

"Look, we've got to talk."

[I couldn't remember the last time Charlie had asked my help for anything, but I managed a casual nod and waited. He played with his menu for a few seconds, then put it down.]

"I need you to do me a favour. The truth is, Emily and I have been going through a bit of a sticky patch. In fact, just recently, we've been avoiding one another altogether. That's why she wasn't there just now to welcome you. Right now, I'm afraid, you get a choice of one or the other of us. A bit like those plays when the same actor's playing two parts. You can't get both me and Emily in the same room at the same time. Rather childish, isn't it?”

"This is obviously a bad time for me to have come. I'll go away, straight after lunch. I'll stay with my Auntie Katie in Finchley."

"What are you talking about? You are not listening. I just told you. I want you to do me a favour."

“I thoughtthat was your way of saying...” (Ishiguro, 2009, pp. 42-43)

Here, Charlie is asking Raymond to do him a favour, but what he says is neither clear nor brief, as he violates the maxims of both quantity and manner. Actually, he is giving redundant and ambiguous information. Despite Charlie's lengthy explanation, what "favour" Raymond is supposed to do for him remains obscure. Naturally, Raymond is misled into thinking what he should do is to leave right away. The underlying reason for Charlie's failure to come straight to the point is that, he has purposely hidden his ill intention of inviting Raymond to his house. This is why even after several turns of talking at the restaurant, Charlie still withholds what the "real favour" is:

“Okay, Ray, listen. What I'm asking you to do is dead simple. All I want is for you to hang about with Emily for the next few days, be a pleasant guest. That’s all. Just until I get back.” (Ishiguro, 2009, p. 45)

In this utterance, Charlie lies to Raymond that the favour is to "hang about with Emily" and "be a pleasant guest”, which violates the maxim of quality. It is Raymond who eventually figures out by himself what the real favour is: 
“So you decided to invite me for a visit. To be Mr. Perspective.” (Ishiguro, 2009, p. 51)

Until now, both Raymond and the readers are illuminated. Charlie has circumvented the truth all the way only because he wants to make use of the "not-so-successful" Raymond to save his endangered relationship with Emily. After all, Raymond doesn't look “the highest of achievers” compared to Charlie and Emily will give up being too demanding on her husband and be on good terms with him again.

The violation of various maxims in these dialogues is revealing. On the one hand, it has cleverly mediated the plot development by slowing down the speed of the story so that readers can experience a delayed satisfaction when they are finally exposed to the truth; on the other hand, it has played an integral part in characterization: Charlie is depicted as a successful yet pretentious hypocrite. The style markers of repetition at the semantic level such as "dead simple”, “all I want”, and "just” show that in Charlie’s opinion, this favour is not a big deal and does no harm to Raymond at all. He is self-centered and completely ignores his friend's feeling. By contrast, Raymond is described as a gentleman: He has not lost temper with Charlie but is nonetheless able to keep calm and restrained. "Mr. Perspective” is an understatement, although he has already realized Charlie's wicked intent to gain a sense of superiority by dwarfing him. In this way, their personality traits are placed in sharp contrast to each other.

\section{Im/politeness Theory and Fictional Dialogue}

"Face" and "im/politeness" are two interconnected concepts in pragmatics. Face is defined by Goffman (1967, p. 5) as "the positive social value a person effectively claims for himself by the line others assume he is taking during a particular contact”. There are two types of face: positive face and negative face: Positive face is the want to be desired or approved by others, whereas negative face is the want to be free from undue impediment (Brown \& Levinson, 1987, p. 62). However, many other researchers like Locher and Bousfield (2008) find that impoliteness is "ubiquitous", such as the face-threatening acts (FTAs) or face-attacking strategies in communication. In fictional dialogues, the analysis of impoliteness can offer stylistic insight into the "mindset of individual characters within a scene” (Bousfield, 2014, p. 130). A prime example of impoliteness in the dialogues is shown below:

Example (3)

[When I was explaining to Emily why it was so difficult to find a flat-mate to share my rent burden, Charlie shouted from the kitchen:]

“That place he's in, it's just not geared up for two people! It's for one person, and one person with a bit more money than he'll ever have!” (Ishiguro, 2009, p. 47)

At one point, Emily suddenly said:

“Oh, honestly Raymond. You let yourself be exploited left, right and centre by that ghastly language school, you let your landlord rip you off silly, and what do you do? Get in tow with some airhead girl with a drink problem and not even a job to support it. It’s like you're deliberately trying to annoy anyone who still gives a shit about you!”

“He can’t expect many of that tribe to survive!” Charlie boomed from the ball. "It's all very well behaving like an adolescent ten years after you've ceased to be one. But to carry on like this when you're nearly fifty!”

"I’m only forty-seven..." 
“What do you mean, you’re only forty-seven?” Emily’s voice was unnecessarily loud given I was sitting right next to her. “Only forty-seven. This 'only', this is what's destroying your life Raymond. Only, only, only. Only doing my best. Only forty-seven. Soon you'll be only sixty-seven and only going round in bloody circles trying to find a bloody roof to keep over your head!”

"He needs to get his bloody arse together!” Charlie yelled down the staircase. "Fucking well pull his socks up till they're touching his fucking balls!” (Ishiguro, 2009, pp. 47-49, italics in the original)

Raymond is bombarded with sarcastic remarks and bitter criticism from Raymond and Emily, who are extremely impolite and even rude to him, which attacks both his positive and negative face.

Positive-face attacking strategies are exemplified in four respects. Firstly, they outspokenly discuss income/money and point out Raymond's predicament by advising him to find a wealthier flat-mate. Secondly, they acutely bring up the topic of age and keep stressing that he is not young any more. The lexical repetition of "only" (eight times, two in italics, adeviation in graphology) projects their growing discontentment with Raymond’s slack lifestyle. Moreover, they rudely criticize him in every way: "be exploited”, "rip you off silly”, "destroying your life". The most noticeable discursive strategy is the multiple use of taboo language like "shit" and "bloody". With his positive face being severely attacked, Raymond's self-esteem and sense of approval are smashed into pieces.

Negative-face threatening propositions are also evident. The last two imperative sentences seemingly fit into the speech act of directives: Charlie urging Raymond to take actions. However, they serve more as threats - given the use of taboo language and exclamation marks - to force Raymond to change his attitude and lifestyle. Surely, Raymond can feel the mounting pressure and imposition on him.

Readers can interpret the three characters and their relationship with more insightful observations. The use of face-attack and face-threat as linguistic strategies by Charlie and Emily precisely displays their arrogant and domineering spirit. In their mindset, wealth and success are the only criteria to judge a person, which makes Raymond a complete "loser”. On top of that, by using all the taboo language, they do not even show the slightest respect to their friend. "I'm only forty-seven" is the only utterance by Raymond in this dialogue. A weak protest as it is, it nevertheless shows Raymond's disagreement with their opinion and his mild personality. He is not as successful as Charlie, but his simple-mindedness and candidness, to some extent, make him a more lovable character.

\section{Turn-Taking in Fictional Dialogue}

Sacks, Schegloff, and Jefferson (1974) reveal that conversation is basically a turn-taking activity and summarize 12 patterns, ranging from "speakers-change recurs, or at least occurs" to "turn-allocation techniques are obviously used” (pp. 700-701). From a stylistic perspective, an analysis of the sequence of turns contributes to the interpretation of character relationships. To this end, Short (1996) lists a set of questions pertaining to the natural characteristics of conversation, like topic control, turn length, and interruptions to identify the most powerful and powerless speakers in dramatic dialogues. Moreover, $\mathrm{Li}$ and $\mathrm{Yu}$ (2001) proposed five aspects from which turn-taking can be studied: initiation and control for topics, turn length, turn-type, interruption, and turn-control strategies. The following extract will be analyzed from these above aspects to illustrate how turn-taking patterns can indicate characters' individual traits and their power relationships. 
Example (4)

(1) Charlie: "I’m at the gate now," he said. "Ray, listen, there’s just one thing that occurred to me. Concerning our strategy."

(2) Raymond: "Our strategy?”

(3) Charlie: “Yes, our overall strategy. Of course, you've realized, this isn't the time for little tweakings of the truth to show yourself in a better light. Absolutely not the time for the small self-aggrandising white lie. No, no. You're remembering, aren't you, why you were given this job in the first place. Ray, I'm depending on you to present yourself to Emily just as you are. So long as you do that, our strategy stays on course.”

(4) Raymond: “Well, look, I’m hardly on course here to come over like Emily’s greatest here...”

(5) Charlie: “Yes, you appreciate the situation and I'm grateful. But something's just occurred to me. There's just one thing, one little thing in your repertoire that won't quite do here. You see, Ray, she's got this idea that you have good musical taste."

(6) Raymond: “Ah...”

(7) Charlie: "Just about the only time she ever uses you to belittle me is in this area of musical taste. It's the one respect in which you aren’t absolutely perfect for your current assignment. So Ray, you've got to promise not to talk about this topic."

(8) Raymond: “Oh, for God's sake...”

(9) Charlie: “Just do it for me, Ray. It’s not much to ask. Just don’t start going on about that... that croony nostalgic music she likes. And if she brings it up, then you just play it dumb. That's all I am asking. Otherwise, you just be your natural self. Ray, I can count on you about this, can't I?"

(10) Raymond: “Well, I suppose so. This is all pretty theoretical anyway. I don’t see us chatting about anything this evening."

(11) Charlie: “Good! So that's settled. Now, let's move to your little problem. You'll be glad to hear I've been giving it some thought. And I've come up with a solution. Are you listening?"

(12) Raymond: “Yes, I’m listening.” (Ishiguro, 2009, pp. 62-63, italics in the original)

Regarding initiation and control of topics, there are primarily two topics here: one about their "strategy" and the other about Raymond's problem, both of which are initiated and controlled by Charlie. In terms of the first topic, in Turn (1), Charlie directly brings up the topic of "our strategy"; in Turns (3) and (7), he gives detailed instructions to Raymond about what he should do; and in Turn (9), he requests for Raymond's reassurance of his promise. In so doing, this topic is constantly kept under Charlie's control. By contrast, Raymond is put in a rather passive position. Although it is against his will to follow Charlie's instruction—see his response in Turn (6) “Ah...” and Turn (8) “Oh, for God's sake...”- -he stands no chance to reject Charlie's demand in the face of his overpowering control. Furthermore, when Charlie proceeds to initiate the second topic in Turn (11), he continues to own the right of control.

Turn-type generally includes initiative turns and responsive turns. It is quite noticeable that Charlie virtually takes all the initiative turns whereas Raymond takes all the responsiveones. As is aforementioned, Charlie's obvious initiative turns occur in Turns (1), (7), (9), and (11). Besides, in the rest two turns of (3) and (5), although Charlie uses the word "yes" as a definite response at first, what he mostly does is to explain rather than to respond, 
so they should be categorized as initiative turns after response. Conversely, nearly all of Raymond's turns are responsive ones: in Turn (2), he repeats Charlie’s word "strategy" with doubt; in Turns (6) and (8), he weakly signals hesitation in response to Charlie's demand; and in Turns (4), (10), and (12), he is apparently responding to Raymond's questions. Overall, Raymond has not taken even a single initiative turn.

So what turn-control strategies have been adopted by Charlie to manipulate the whole conversation? According to $\mathrm{Li}$ and $\mathrm{Yu}$ (2001), there are two types of turn-control strategies: one being the present speaker choosing the next speaker or conceding the right of topic control and the other being the speaker clinging to the right of topic control and carrying on with his/her turns. Charlie generally adopts the first strategy: He timely and adequately concedes his right of talk to Raymond in an effort to keep him engaged in the conversation and solicits his response. This is achieved by two stylistic devices: the syntax of imperatives and the (tag) questions, including “you’ve got to promise not to talk about this topic” (in Turn 7), “Just do it for me” (in Turn 9), "you just be your natural self” (in Turn 9), and "let’s move to your little problem” (in Turn 9). In these sentences, Charlie is performing the speech act of “directives”: requesting Raymond to do certain things for him or directing him to another topic. In so doing he intentionally gives over his right of turn to Raymond, who is expected to make proper response in return. In addition, tag questions such as “You're remembering, aren’t you?” (in Turn 3) and “I can count on you about this, can’t I?” (in Turn 9) as well as the question “Are you listening?” (in Turn 11) directly draw Raymond's attention and solicit a positive reply from him. By these means, Charlie is in a firm control of their conversation.

Turn length is another perspective from which turn-taking can be studied. Turn length, as it suggests, is concerned with the length and the number of turns in a dialogue. A close study of the above dialogue is shown below:

Table 1

Turn length of Charlie and Raymond in Example (4)

\begin{tabular}{llll}
\hline Character & Word count & Number of turns & Average length \\
\hline Charlie & 272 & 6 & 45.3 \\
Raymond & 43 & 6 & 7.2 \\
\hline
\end{tabular}

Despite the same number of turns, Charlie's average length of turn is considerably longer, 6 times that of Raymond's. All of Charlie's turns contain three sentences or more, while Raymond's turns contain only two or four words in Turns (2), (8), (12) and only one word in Turn (6).To put it simply, Charlie takes control of the conversation by using much longer sentences with a lot more words.

This examplefully reveals Charlie's indisputable dominance and Raymond's subordinate status in their relationship. For Charlie, wealth and success means everything while musical taste is only a tiny little thing—note his repetitive use of "one”, "only", and "just” in the following sentences: "just one thing, one little thing in your repertoire”, “Just about the only time”, and "It's the one respect”. Since Charlie owns wealth and success, he is naturally confident in controlling their talk by initiating and changing topic, using various turn-control strategies as well as longer turn-length. Moreover, he is also extremely sophisticated in that he knows too well and seizes upon Raymond's "soft rib": He is too weak in personality to say no to anyone or anything. "I'm depending on you" and "I can count on you" are actually "sugar-coated bullets" targeted at 
Raymond's weaknesses. On the contrary, Raymond, being poor, unsuccessful plus obedient in nature, is totally powerless, passive and thus in a disadvantaged position. Although he harbors the feeling of reluctance to hide his musical taste, he fails to turn down Raymond's request and eventually does what he promises. At a deeper level, their power relationship is an epitome of the mainstream ideology of contemporary society that whoever owns money owns discursive power and spiritual pursuit/musical taste seems to be of little account. Finally, the author wishes to invoke readers' appreciation and respect for music, which is the the matic significance running through all five short stories in Nocturnes.

\section{Conclusion}

Literary pragmatics and stylistics are inextricably linked toeach other and the two fields have been moving even closer together in recent years (Leech \& Short, 2001; Hickey, 1993). On the one hand, research in stylistics has broadened the field of pragmatics by spurring scholars to investigate and explain the "relatively long and complex acts of verbal communication” (Warner, 2014, p. 363); on the other hand, pragmatics has assisted scholars to understand "how style intersects with contexts of use and interactants' perceptions thereof” (Warner, 2014, p. 364). Specifically, pragmatic theories like speech acts and im/politeness can be integrated with stylistic theories of characterization (Culpeper, 2001) and narrative development (Labov \& Waletzky, 1967) to examine the functions and essence of communication, the process when language users use their linguistic skills to "do things with words" (Austin, 1962).

The current study has conducted a detailed analysis of four fictional dialogues in Ishiguro's short story "Come Rain or Come Shine" in Nocturnes. Effort has been made to reveal the stylistic features as well as the artistic effects in these dialogues in the light of the cooperative principle, the im/politeness theory, and the turn-taking theory. They have proven to be empowering analytical tools in guiding us to stylistically read character speech forms and interpret textual cues in conversation. The stylistic features embodied in the fictional dialogues have essential role to play in helping to achieve characterization and mediate plot development of the story. Hence, readers can gain a better insight into the characters' traits, mindset, and their relationships with one another as well as the acceleration and deceleration in the narrative development.

\section{References}

Austin, J. L. (1962). How to do things with words. Oxford: Oxford University Press.

Bousfield, D. (2014). Stylistics, speech acts and im/politeness theory. In M. Burke (Ed.), The routledge handbook of stylistics (pp. 118-135). London and NewYork: Routledge.

Brown, P., \& Levinson, S. C. (1987). Politeness: Some universals in language usage. Cambridge: Cambridge University Press.

Culpeper, J. (2001). Language and characterisation: People in plays and other texts. London: Longman.

Goffman, E. (1967). Interaction ritual. Chicago: Aldine Publishing.

Grice, H. P. (1975). Logic and conversation. In P. Cole and J. Morgan (Eds.), Syntax and semantics, III: Speech acts (pp. 41-58). New York: Academic Press.

Hickey, L. (1993). Stylistics, pragmatics and pragmastylistics. Revue Belge de Philologie et d'Histoire, 71(3), 573-586.

Ishiguro, K. (2009). Nocturnes: Five stories of music and nightfall. London: Faber \& Faber.

Labov, W., \& Waletzky, L. (1967). Narrative analysis: Oral versions of personal experience. In J. Helm (Ed.), Essays on the verbal and visual arts (pp. 12-44). Seattle: University of Washington Press.

Lambrou, M. (2014). Stylistics, conversation analysis and the cooperative principle. In M. Burke (Ed.), The routledge handbook of stylistics (pp. 136-154). London \& NewYork: Routledge. 
Leech, G. N., \& Short, M. H. (2001). Style in fiction: A linguistic introduction to English fictional prose. Beijing: Foreign Language Teaching and Research Press.

Lewis, B. (2000). Contemporary world writers: Kazuo Ishiguro. Manchester: Manchester University Press.

Li, H. D., \& Yu, D. M. (2001). Power relations, characterization, and plot development revealed by a turn-taking analysis. Journal of PLA University of Foreign Languages, 24(2), 26-30.

Locher, M., \& Bousfield, D. (2008). Impoliteness and power in language. In D. Bousfield and M. Locher (Eds.), Impoliteness in language (pp. 1-17). Berlin: Mouton de Gruyter.

Nørgaard, N., Busse, B., \& Montoro, R. (2010). Key terms in stylistics. London: Continuum.

Petry, M. (1999). Narratives of memory and identity: The novels of Kazuo Ishiguro. Frankfurt am Main: Peter Lang.

Rimmon-Kenan, S. (2002). Narrative fiction: Contemporary poetics. London \& NewYork: Routledge.

Sacks, H., Schegloff, E. A., \& Jefferson, G. (1974). A simplest systematics for the organization of turn-taking for conversation. Language, 50(4), 696-735.

Short, M. (1996). Exploring the language of poems, plays and prose. Harlow, England: Longman.

The Official Website of the Nobel Prize. (2017). The Nobel Prize in Literature 2017 Press Release. Retrieved from https://www.nobelprize.org/nobel_prizes/literature/laureates/2017/press.html

Warner, C. (2014). Literary pragmatics and stylistics. In M. Burke (Ed.), The routledge handbook of stylistics (pp. 362-377). London and NewYork: Routledge. 